ARTICLE

\title{
Highly active oxygen reduction non-platinum group metal electrocatalyst without direct metal-nitrogen coordination
}

\author{
Kara Strickland ${ }^{1}$, Elise Miner ${ }^{1, \dagger}$, Qingying Jia ${ }^{1}$, Urszula Tylus ${ }^{1, \dagger}$, Nagappan Ramaswamy ${ }^{1, \dagger}$, Wentao Liang ${ }^{2}$, \\ Moulay-Tahar Sougrati ${ }^{3}$, Frédéric Jaouen ${ }^{3} \&$ Sanjeev Mukerjee ${ }^{1}$
}

Replacement of noble metals in catalysts for cathodic oxygen reduction reaction with transition metals mostly create active sites based on a composite of nitrogen-coordinated transition metal in close concert with non-nitrogen-coordinated carbon-embedded metal atom clusters. Here we report a non-platinum group metal electrocatalyst with an active site devoid of any direct nitrogen coordination to iron that outperforms the benchmark platinumbased catalyst in alkaline media and is comparable to its best contemporaries in acidic media. In situ X-ray absorption spectroscopy in conjunction with ex situ microscopy clearly shows nitrided carbon fibres with embedded iron particles that are not directly involved in the oxygen reduction pathway. Instead, the reaction occurs primarily on the carbon-nitrogen structure in the outer skin of the nitrided carbon fibres. Implications include the potential of creating greater active site density and the potential elimination of any Fenton-type process involving exposed iron ions culminating in peroxide initiated free-radical formation.

\footnotetext{
${ }^{1}$ Northeastern University Center for Renewable Energy Technology, Department of Chemistry and Chemical Biology, Northeastern University, 317 Egan Research Center, 360 Huntington Avenue, Boston, Massachusetts 02115, USA. ${ }^{2}$ Department of Biology, Northeastern University, 134 Mugar Life Sciences, 360 Huntington Avenue, Boston, Massachusetts 02115, USA. ${ }^{3}$ Institut Charles Gerhardt de Montpellier-UMR 5253, 2 Place Eugéne Batallion, Montpellier Cedex 5 34095, France. † Present Addresses: Massachusetts Institute of Technology, 77 Massachusetts Avenue, Room 6-426, Cambridge, Massachusetts 02139, USA (E.M.); Los Alamos National Laboratory, PO Box 1663, MPA-11, MS D429, Los Alamos, New Mexico 87545 USA (U.T.); General Motors Corporation, Global Fuel Cell Activities Division, 895 Joslyn Avenue, Pontiac, Michigan 48340 USA (N.R.). Correspondence and requests for materials should be addressed to S.M. (E-mail: s.mukerjee@neu.edu).
} 
$\mathrm{R}$ eplacement of noble metal electrocatalysts such as those used in oxygen reduction reaction (ORR) is a research goal for electrochemists involved in the low and medium temperature proton-conducting membrane fuel cells. The high efficiency and theoretical energy density of the $\mathrm{H}_{2}$ /air fuel cell technology makes it a potential alternative for the replacement of internal combustion engine-based power sources in applications such as transportation and decentralized power and so on.

Three decades of effort towards engendering non-platinum group metal (non-PGM) electrocatalyst has seen a slow but promising evolution of activity for ORR as well as our general understanding of the catalytic active site. Most of these prior efforts have relied on the presence of nitrogen-coordinated sites with or without a transition metal, such as Fe. Despite making progress the current state of the art non-PGM electrocatalyst has yet to achieve the catalytic activity of platinum and thus remains an important research area.

Among the key breakthroughs in this arena were those by Jasinski et al. ${ }^{1}$, who was the first to report the oxygen reduction capabilities of cobalt phthalocyanine in basic media. This was followed with that of Jahnke et al. ${ }^{2}$, who reviewed the activity of various $\mathrm{N}_{4}$-metal chelates and recognized the necessity of heat treatments that resulted in the improvement of stability in basic media and significant enhancement of activity and stability in acidic media. Heat treatment of an existing metal-nitrogen $\left(\mathrm{M}-\mathrm{N}_{x}\right)$-coordinated macrocycles dominated the early research of non-PGMs but Yeager and co-workers ${ }^{3}$ caused a principle shift resulting in a significant jump in activity by transitioning to nonmacrocyclic precursor materials. More recently, Zelenay et al. ${ }^{4,5}$ and Dodelet et al. ${ }^{6,7}$ have demonstrated significant enhancement using the non-macrocyclic precursor-based active-site evolution route. Generally accepted notion of active sites for ORR, formed as a result of a series of heat treatment and etching steps, involved some form of $\mathrm{M}-\mathrm{N}_{x}$ sites $^{8,9}$. In addition, presence of some type of transition metal/metal oxides (those involving some degree of metal-metal bonds) are also typically reported especially for materials heat treated at temperatures $>800^{\circ} \mathrm{C}$ (ref. 10). It was generally believed that these moieties were catalytically inactive due to their thermodynamic instability in low $\mathrm{pH}$ environment or their inaccessibility to oxygen if isolated/protected from the electrochemical environment by layers of carbon ${ }^{11,12}$. More recently, their direct involvement in acidic media is reported in a cascade of $2 \mathrm{e}^{-}$reduction steps via peroxide intermediate ${ }^{13-15}$.

The role of transition metal/metal oxides has, however, been debated, for example, Kramm et al. ${ }^{16}$ claimed that the formation of metal/metal oxides was detrimental to the overall activity of their non-PGM electrocatalyst. Using Mössbauer spectroscopy, they investigated Fe-based non-PGMs and identified five different types of iron species present, but attributed activity to only two types of the iron, both of which were coordinated to nitrogen.

While most of the recent non-PGM literature has focused on a metal-based active sites, there have been several reports of nitrogen-doped (N-doped) carbons with 'metal-free' active sites $^{17,18}$. Stevenson et al. ${ }^{19}$ elucidated the ORR pathway in neutral and basic media and found nitrogen-doping-enhanced ORR activity due to improved adsorption of $\mathrm{O}_{2}$ and decomposition of peroxide intermediate. Ozkan et al. ${ }^{20}$ were the first to demonstrate that $\mathrm{N}$-doped carbons have ORR activity in acidic media and attributed this activity to the increased edge planes of the graphite with pyridinic nitrogen. Dai et al. ${ }^{21}$ investigated a $\mathrm{N}$-doped graphene in alkaline media and provided further proof of these 'metal-free' active sites. Deng et al. $^{22}$ reported a material consisting of iron nanoparticles (Fe NPs) encapsulated in carbon nanotubes (CNTs) that was shown to effectively catalyse ORR in the acidic environment of a proton exchange membrane (PEM) fuel cell. Their density function theory (DFT) calculations revealed that the interaction between the Fe and the $\mathrm{C}$, in the wall of the CNT, significantly enhanced the activity of the CNTs for ORR catalysis. These examples constitute a small sample from the literature of a growing consensus that there are 'metal-free' active sites present in non-PGMs. However, the synthesis procedure for all of previously reported electrocatalysts invariably involve a metal component (typically iron) and the final electrocatalyst cannot be declared completely devoid of $\mathrm{Fe} \mathrm{NPs}$ and/or iron carbides $\left(\mathrm{Fe}_{3} \mathrm{C}\right)^{4,23,24}$. Since these moieties are present in the electrocatalyst, their role in ORR cannot be ruled out without in situ evidence.

This work via our spectroscopic evidence and the use of metal organic framework (MOF) as a template to form active sites with and without transition elements provides evidence of creation of metal-free active sites for ORR with no involvement of active $\mathrm{Fe}-\mathrm{N}_{x}$ sites. In this work, a MOF based on $\mathrm{Zn}$ (ZIF-8) is used as an encapsulator for $\mathrm{Fe}$ chelated with a nitrogen complex. Encapsulation of the chelated iron complex in the pores is employed in an effort to obtain equal distribution and high density of active sites. ORR is investigated in alkaline and acidic media to better understand the reduction mechanism of the studied electrocatalyst. MOF-based structures with and without incorporation of iron precursor are heat treated and etched to form the active electrocatalyst, enabling proper comparison with samples derived wherein no iron was chelated. This is in contrast to previous reports where a complete absence of iron cannot be claimed $^{19-22,25}$. By combining electrochemical and spectroscopic methods, we are able to show that while the derived iron containing non-PGM catalysts exhibits high ORR activities, coordination environment for iron is predominantly $\mathrm{Fe} / \mathrm{Fe}_{x} \mathrm{C}$ particulate in nature. Using in situ X-ray absorption spectroscopy (XAS), we are able to characterize the iron coordination of the electrocatalyst under actual simulated operating conditions of a PEM fuel cell and are unable to detect any direct $\mathrm{Fe}-\mathrm{N}_{x^{-}}$ coordinated sites present in the non-PGM electrocatalyst. In addition to the absence of direct $\mathrm{Fe}-\mathrm{N}_{x}$ coordination, we also show the complete absence of any direct involvement of the Fe in the electrocatalytic pathway as a result of its presence subsurface to the carbo-nitrided fibres and hence its important implication in avoidance of any Fenton-type process related to onset of peroxide-induced free-radical formation as detailed earlier ${ }^{26}$.

\section{Results}

Physicochemical characterization. The $2 \theta$ values and symmetry of the powder XRD of FePhen@MOF (before heat treatment) as compared with the purchased Basolite (Sigma, Basolite Z1200) confirm the formation of the crystalline MOF structure (Supplementary Fig. 1). The concomitant diminished intensity of the signal from FePhen@MOF (Supplementary Fig. 2) is indicative of the presence of guest molecules within the MOF structure as a result of encapsulation (Supplementary Note 1), this is in agreement with similar observations reported earlier ${ }^{27}$. In addition, the absence of the diffraction lines characteristic of 1,10-phenanthroline (Supplementary Fig. 1; N-chelating agent for Fe) imply that it is not present as a separate entity in crystalline form. However, ultraviolet-visible (ultraviolet-vis) spectroscopy (Supplementary Table 1) confirmed retention of 1,10-phenanthroline in the FePhen@MOF and thermogravimetric analysis indicated its enhanced thermal stability as a result of the encapsulation (Supplementary Fig. 3). Further, FePhen@MOF exhibited a much smaller Brunauer-Emmet-Teller (BET) (Supplementary Fig. 4) surface area than the commercial analogous Basolite (424 versus $\left.1813 \mathrm{~m}^{2} \mathrm{~g}^{-1}\right)$, which is likely attributable to the encapsulation of the chelated iron complex within the MOF pore reducing the overall pore volume (Supplementary Fig. 5). 
The FePhen@MOF material was subjected to an initial heat treatment $\left(1,050^{\circ} \mathrm{C}\right)$ in Ar atmosphere (FePhen@MOF-Ar) for a tailored breakdown of the MOF structure and removal of $\mathrm{Zn}$ nodes via sublimation resulting in an initial rendering of a carbonaceous material with significant electronic conductivity. The XRD powder pattern (Fig. 1a; Supplementary Fig. 6) shows emergence of an elevated baseline typical for presence of amorphous material as well as diffraction lines of graphite and some iron phases (Fig. 1b; iron-Fe (Im-3 m) and iron carbide$\left.\mathrm{Fe}_{5} \mathrm{C}_{2}(\mathrm{C} 2 / \mathrm{c})\right)$. However, we were not able to accurately determine the exact stoichiometry of the iron carbide using XRD. An additional heat treatment $\left(1,050^{\circ} \mathrm{C}\right)$ in ammonia (FePhen@ $\mathrm{MOF}-\mathrm{ArNH}_{3}$ ) led to the formation of several new diffraction lines (Supplementary Fig. 6) that indicate the incorporation of nitrogen into the carbon scaffold in the vicinity of the iron. These new diffraction lines post $\mathrm{NH}_{3}$ heat treatment show emergence of Fe nitrides $\left(\mathrm{Fe}_{3} \mathrm{~N}_{1.59}\right.$ (P6322) and $\left.\mathrm{Fe}_{2} \mathrm{~N}(\mathrm{P}-31 \mathrm{~m}(162))\right)$; however, $\mathrm{XRD}$ alone could not unambiguously determine the exact nitrogen content. Comparing these XRD results with those obtained from Basolite-ArNH $\mathrm{An}_{3}$ (subjected to the same heat treatments as FePhen@MOF-ArNH${ }_{3}$; Fig. 1a) lead us to believe that in the latter case the iron is converted to its metallic form during the initial argon heat treatment and subsequently acts as a catalyst that graphitizes the vicinal carbon-nitrogen's from MOF precursor. The second heat treatment in ammonia, thus, is effective in etching a portion of the remaining amorphous carbon $^{28}$ and introducing nitrogen functionalities into the carbon scaffold. The BET surface area increased with each heat treatment (Supplementary Fig. 4) resulting in FePhen@MOF-ArNH exhibiting a surface area of $1,200 \mathrm{~m}^{2} \mathrm{~g}^{-1}$, comparable to that of the original Basolite (no heat treatment). Basolite and FePhen@MOF are originally microporous $(<20 \AA)$ materials; however, the microporosity is increased with each heat treatment and mesopores (20-40 $)$ are introduced (Supplementary Fig. 7) to FePhen@MOF-ArNH

XAS was used to further probe the local coordination of the iron present after heat treatment (Supplementary Note 2). Fourier transform (FT) of the extended EXAFS of the Fe K-edge measured on the electrode in situ (held at $0.3 \mathrm{~V}$, free of adsorbates) was dominated by a peak at $\sim 2.2 \AA$, which can be fit with $\mathrm{Fe}-\mathrm{Fe}$ scattering (Supplementary Fig. 8; Supplementary Table 2). Qualitative comparison of the FePhen@MOF- $\mathrm{ArNH}_{3}$ spectrum with the spectra of the standard metallic iron foil (Fe foil) and $\mathrm{Fe}_{3} \mathrm{C}$ standard suggests that the iron is predominantly converted to its metallic state with a minor carbide phase. However, it should be noted that an inherent limitation of XAS is the inability to differentiate between $\mathrm{C}, \mathrm{N}$ and $\mathrm{O}$ neighbouring atoms (Supplementary Note 3). Therefore, we cannot use FT EXAFS to conclusively identify the presence or absence of $\mathrm{Fe}$ nitrides or carbides in the final catalyst.
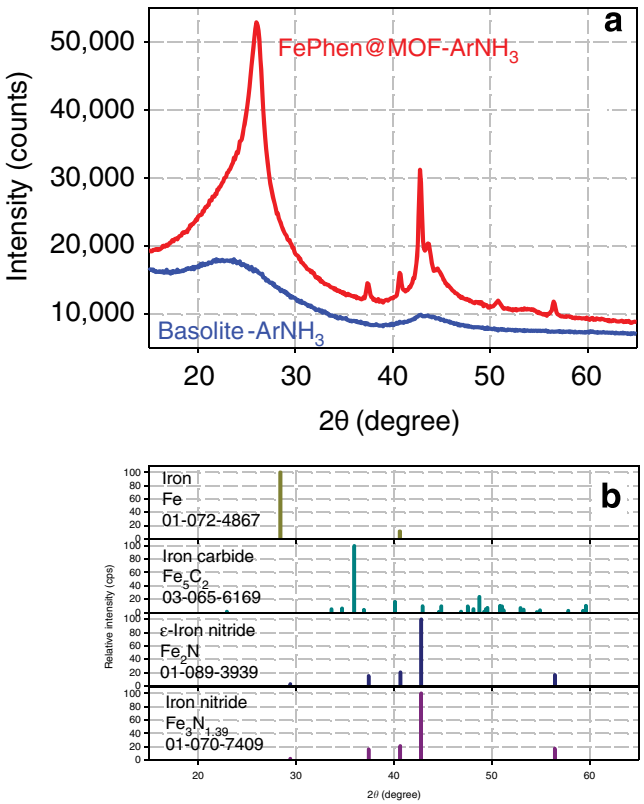

g

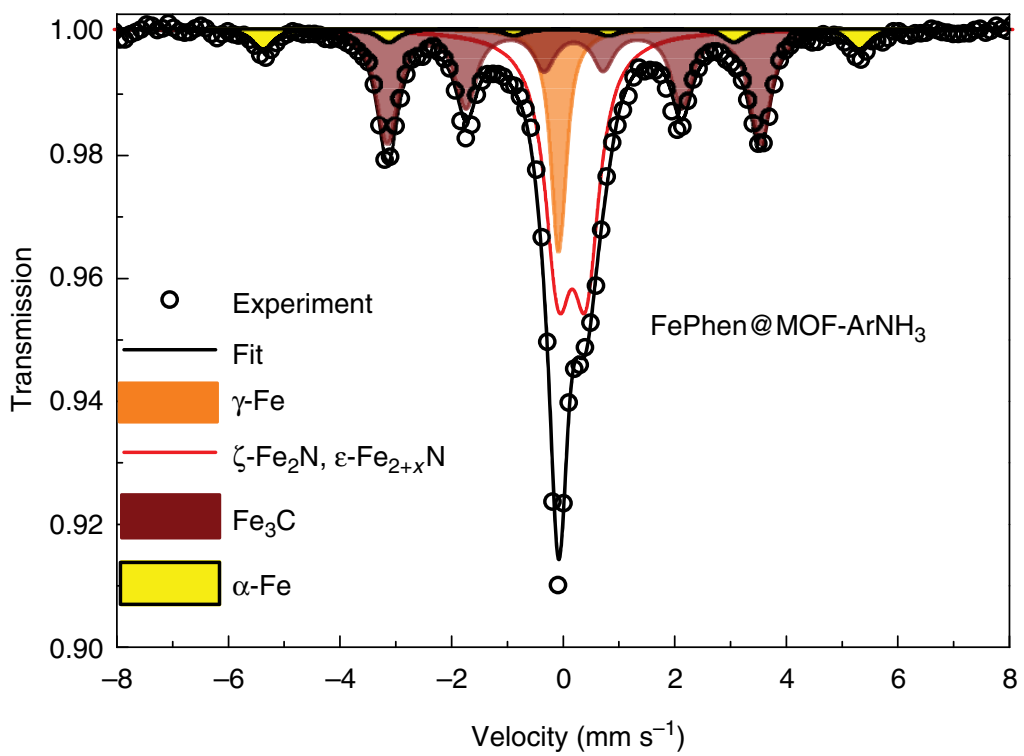

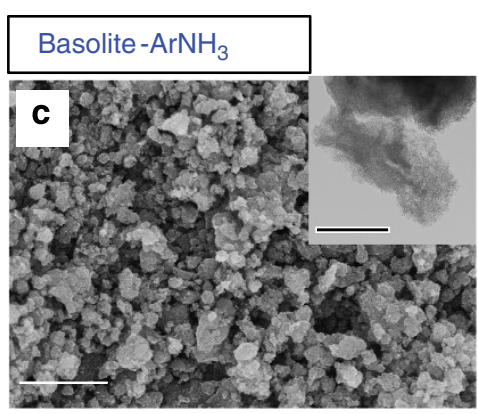
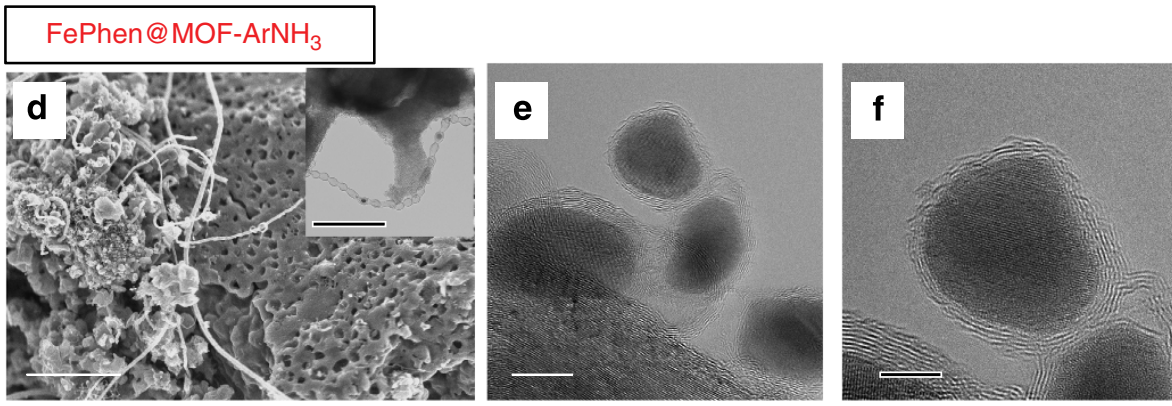

Figure 1 | Physicochemical characterization. (a) X-ray diffraction pattern of FePhen@MOF-ArNH $\mathrm{H}_{3}$ and Basolite-ArNH $\mathrm{H}_{3}$. (b) Diffraction patterns of iron, iron carbide and iron nitrides. (c) SEM image of Basolite- $\mathrm{ArNH}_{3}$. Scale bar, $2 \mu \mathrm{m}$. Inset TEM image of amorphous carbon. Scale bar, $100 \mathrm{~nm}$. (d) SEM image of FePhen@MOF-ArNH ${ }_{3}$. Scale bar, $2 \mu \mathrm{m}$. Inset TEM image of bamboo-jointed CNT. Scale bar, $100 \mathrm{~nm}$. (e) HR-TEM image of iron

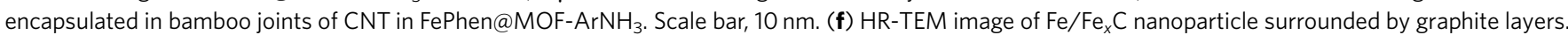
Scale bar, $5 \mathrm{~nm}$. (g) ${ }^{57} \mathrm{Fe}$ Mössbauer spectrum of FePhen@MOF- $\mathrm{ArNH}_{3}$ measured at room temperature. 
The different iron coordination environments in FePhen@ MOF-ArNH 3 were further investigated with ex situ ${ }^{57} \mathrm{Fe}$ Mössbauer spectroscopy (Fig. 1g). The absorption spectrum measured at room temperature (RT) was successfully fit with four components: (1) paramagnetic $\gamma$-Fe, (2) ferromagnetic $\mathrm{Fe}_{3} \mathrm{C}$, (3) ferromagnetic $\alpha$-Fe and (4) $\xi-\mathrm{Fe}_{2} \mathrm{~N}$. (Supplementary Table 3; Supplementary Note 4).

The surface morphology of FePhen@MOF-ArNH $\mathrm{H}_{3}$ (Fig. 1d) was probed with SEM and revealed that the heat treatment produces several different carbon morphologies. The decomposition of the MOF framework and evaporation of $\mathrm{Zn}$ above $550{ }^{\circ} \mathrm{C}$ (ref. 29) forms a porous carbon framework. In addition, some of the Fe agglomerated into Fe NPs that catalysed the growth of CNTs of varying sizes and possessed distinct bamboo-like joints, which are characteristic of $\mathrm{N}$-doped carbon ${ }^{19,30}$. High-resolution TEM revealed that Fe-particles were contained within the compartments of the CNTs (Fig. 1e,f) and the compartment wall thickness varied with the size of the Fe-particles. Conversely, the surface morphology of Basolite- $\mathrm{ArNH}_{3}$ (Fig. 1c) had no CNTs present, which suggests that the iron present in FePhen@MOF primarily acts as a catalyst for the graphitization of carbon.

Electrochemical performance. Basolite (Basolite- $\mathrm{ArNH}_{3}$ ) was subjected to the same heat treatment as FePhen@MOF-ArNH $\mathrm{H}_{3}$ (that is, Ar followed with $\mathrm{NH}_{3}$ at 1,050 and $1,050{ }^{\circ} \mathrm{C}$, respectively) to be used as a reference for a $\mathrm{Fe}$-free catalyst in our rotating ringdisk electrode (RRDE) studies. Typically, $\mathrm{Pt} / \mathrm{C}$ is known to proceed predominantly through the $4 \mathrm{e}^{-}$path in both alkaline and acidic media, as long as the surface is free of poisonous adsorbates $^{31}$. However, in alkaline media, it has been shown that specifically adsorbed hydroxyl species non-covalently interact with solvated oxygen molecules and the reduction proceeds through a $2 \mathrm{e}^{-}$outer sphere charge transfer process producing the peroxide anion intermediate $\left(\mathrm{HO}_{2}^{-}\right)$, (as detected at the ring electrode of RRDE at $\sim 0.8 \mathrm{~V}$ (ref. 32); Supplementary Fig. 9) followed with an additional concerted $2 \mathrm{e}^{-}$reduction step to water. The same report showed that in contrast to this a nonPGM catalyst derived from heat-treated Fe-tetraphenylporphyrin $(\mathrm{Fe}-\mathrm{TPP})^{32}$ exhibits an exclusive inner sphere concerted $4 \mathrm{e}^{-}$ reduction in alkaline media due to direct adsorption of $\mathrm{O}_{2}$ and the kinetically favoured hydrogen peroxide reduction reaction ${ }^{32}$. Central to this mechanism was its correlation with $\mathrm{Fe}-\mathrm{N}_{x}$ (predominant four coordination) active sites formed in the divacant defects in the carbon basal plane ${ }^{32}$. In alkaline media, Basolite- $\mathrm{ArNH}_{3}$ has an onset potential of $0.97 \mathrm{~V}$ (Fig. 2a) and the oxidation of the peroxide intermediate detected at the ring electrode coincides with the onset of reduction at the disk (Supplementary Fig. 9). This indicates that the peroxide is not stabilized on the active site and ORR proceeds predominantly through a $2 \mathrm{e}^{-}$reduction pathway. However, the presence of the iron in FePhen@MOF-ArNH $\mathrm{N}_{3}$ provides a $60 \mathrm{mV}$ improvement (with respect to Basolite- $\mathrm{ArNH}_{3}$ ) in the onset potential (1.03 versus $0.97 \mathrm{~V}$ ) as well as a $40 \mathrm{mV}$ improvement in half-wave potential $\left(E_{1 / 2}\right)(0.86$ versus $0.82 \mathrm{~V}$; Fig. $2 \mathrm{a})$. In addition, the onset of the peroxide oxidation peak at the ring electrode is shifted cathodically to $\sim 0.45 \mathrm{~V}$ (Supplementary Fig. 9). Peroxide oxidation at $0.45 \mathrm{~V}$ is also observed on $\mathrm{Pt} / \mathrm{C}$ electrocatalyst (Supplementary Fig. 9) and has been attributed to $2 \mathrm{e}^{-}$reduction of oxygen by the quinone functionalities of the carbon support ${ }^{32}$. However, FePhen@MOF-ArNH ${ }_{3}$ did not demonstrate enhanced hydrogen peroxide reduction reaction activity (Supplementary Fig. 10) and therefore this increase in activity cannot be attributed to peroxide specific $\mathrm{Fe}-\mathrm{N}_{x}$ sites. These electrochemical results suggest incorporation of iron moieties in FePhen@MOF- $\mathrm{ArNH}_{3}$ in a different coordination environment as compared with classical $\mathrm{Fe}-\mathrm{N}_{x}$ active-site-based electrocatalyst (as exemplified by Fe-TPP). Considering the XRD, SEM and TEM results presented above, it can be conjectured that $\mathrm{Fe}$ is present in the form $\mathrm{Fe} / \mathrm{Fe}_{x} \mathrm{C}$, subsurface to the $\mathrm{N}$-doped carbon overlayer. As shown later in this article based on in situ element-specific XAS spectroscopy results, subsurface $\mathrm{Fe} / \mathrm{Fe}_{x} \mathrm{C}$ are inactive towards $\mathrm{O}_{2}$ adsorption, and the ORR activity predominantly appears to arise from the $\mathrm{N}$-doped carbon surface. It appears that the presence of the subsurface $\mathrm{Fe} / \mathrm{Fe}_{x} \mathrm{C}$ acts to stabilize the peroxide intermediate on the active site in the alkaline medium.

When the same experiment was conducted in acidic media, FePhen@MOF- $\mathrm{ArNH}_{3}$ exhibited a $90 \mathrm{mV}$ improvement in $E_{1 / 2}$ $(0.77$ versus $0.68 \mathrm{~V})$ for ORR when compared with Basolite$\mathrm{ArNH}_{3}$ (Fig. 2a). This is evidenced by the higher onset potential $(E=0.93$ versus $E=0.89 \mathrm{~V})$ of FePhen@MOF-ArNH $\mathrm{Ar}_{3}$ versus Basolite- $\mathrm{ArNH}_{3}$ in oxygen saturated $0.1 \mathrm{M}$ perchloric acid $\left(\mathrm{HClO}_{4}\right)$. More interestingly, the onset of peroxide oxidation for both of the non-PGM electrocatalyst in acidic media now coincides with the onset of ORR (Supplementary Fig. 11). When switching to the low $\mathrm{pH}$ environment, the peroxide intermediate is no longer present as anion, but as a neutral species $\left(\mathrm{H}_{2} \mathrm{O}_{2}\right)$ that has been shown to desorb more easily into the bulk electrolyte due to the absence of intermediate stabilization on the active site $^{32}$. Our results confirm this finding, but we also find that the oxidative ring current of Basolite- $\mathrm{ArNH}_{3}$ is an order of magnitude higher than FePhen@MOF-ArNH $\mathrm{A}_{3}$. This suggests that the presence of the iron moieties in FePhen@MOF-ArNH still promotes the selectivity towards the $4 \mathrm{e}^{-}$ORR pathway in acidic media. As mentioned above in our discussions on alkaline media results, subsurface $\mathrm{Fe}$ appears to be critical in the electrocatalysis in close concert with synergistic effect of $\mathrm{N}$-doped carbon (Fig. 1e,f). Independent DFT calculations ${ }^{22,33}$ conducted on distinct Fe-based non-PGM catalysts support our theory that the electronic properties of the carbon could be enhanced by the interaction with nitrogen and $\mathrm{Fe}$ enabling easier adsorption of $\mathrm{O}_{2}$ and reduction to $\mathrm{H}_{2} \mathrm{O}$.

The inherent ORR activity exhibited by RRDE measurements of FePhen@MOF-ArNH $\mathrm{N}_{3}$ in acidic media (Fig. 2a) are corroborated by single PEM fuel cell measurements. Polarization and durability curves were collected, on a membrane electrode assembly (MEA) employing a FePhen@MOF- $\mathrm{ArNH}_{3}$ cathode, under the US Department of Energy (US DOE) suggested testing conditions of $80{ }^{\circ} \mathrm{C}, 100 \%$ relative humidity, 1 bar partial pressure of $\mathrm{H}_{2} / \mathrm{O}_{2}$ (1.5 bar total pressure) and/or 0.4 bar partial pressure of $\mathrm{O}_{2}$ in $\mathrm{H}_{2}$ /air (2.5 bar total pressure). In a $\mathrm{H}_{2} / \mathrm{O}_{2}$ fuel cell, FePhenMOF-ArNH $\mathrm{MEA}_{3}$ generated a kinetic current density of $>100 \mathrm{~mA} \mathrm{~cm}^{-2}$ at $0.8 \mathrm{~V}_{\mathrm{iR}}$ free (Fig. 2b), ranking it as one of the most active non-PGM cathodes reported to date with no $\mathrm{FeN}_{x}$ moieties (as demonstrated in the following section). Non-PGM cathodes require higher catalyst loadings $\left(3 \mathrm{mg} \mathrm{cm}^{-2}\right.$ compared with $0.4 \mathrm{mg}_{\mathrm{Pt}} \mathrm{cm}^{-2}$ for $\mathrm{Pt} / \mathrm{C}$ ) that traditionally introduces masstransport limitations; however, FePhen@MOF-ArNH $\mathrm{AH}_{3}$ was able to reach $75 \%$ the power density of a state-of-the-art $\mathrm{Pt} / \mathrm{C}$ cathode run under the same conditions. Although microporosity is considered a prerequisite for good catalytic activity in nonPGMs, mesopores are essential for effective mass transport, and we believe the increase in mesoporosity (Supplementary Fig. 7) on heat treatment imparted superior mass-transport properties that result in the enhanced activity. On switching to air as the oxidant the FePhen@MOF-ArNH $\mathrm{N}_{3}$ MEA (Fig. 2c) reached a kinetic current density of $50 \mathrm{~mA} \mathrm{~cm}^{-2}$ at $0.8 \mathrm{~V}_{\text {non-iR corrected }}$ and a peak power density of $0.38 \mathrm{~W} \mathrm{~cm}^{-2}$ at $0.4 \mathrm{~V}$ (or a current density of $1 \mathrm{~A} \mathrm{~cm}^{-2}$, the current DOE performance target), $\sim 60 \%$ the power density reached by the Pt-based cathode under the same operating conditions. To our knowledge, this is the highest reported $\mathrm{H}_{2}$ /air activity to date by a non-PGM cathode 

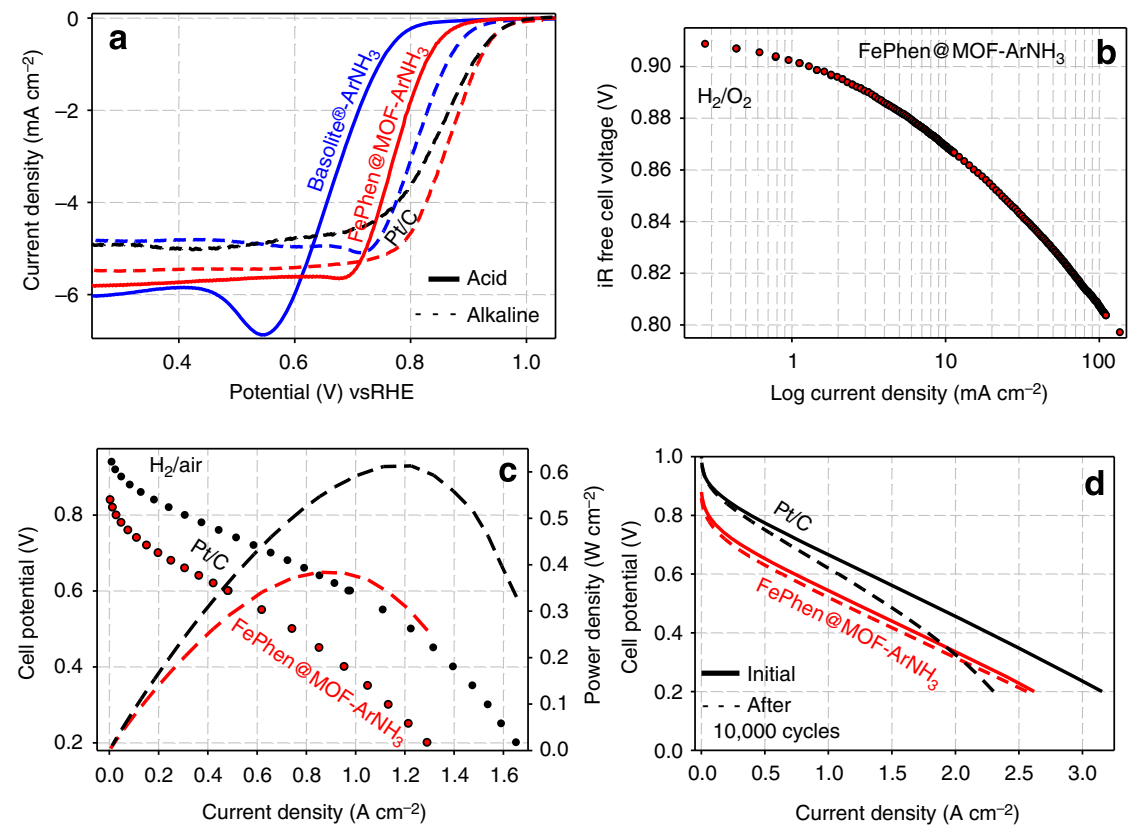

Figure 2 | RDE and fuel cell testing. (a) Rotating disk electrode (RDE) ORR polarization plots collected with FePhen@MOF-ArNH $\mathrm{M}_{3}, \mathrm{Basolite}^{-\mathrm{ArNH}_{3}}$ and Tanaka Pt/C in $\mathrm{O}_{2}$ saturated electrolyte $\left(0.1 \mathrm{M} \mathrm{HClO}_{4}\right.$ and $\left.0.1 \mathrm{M} \mathrm{KOH}\right)$ at $20 \mathrm{mVs}^{-1}$ with rotation rate of 1,600 r.p.m. at room temperature. (b) $\mathrm{H}_{2} / \mathrm{O}_{2}$ fuel cell iR-corrected Tafel plot for FePhen@MOF-ArNH $\mathrm{H}_{3}$ cathode (loading of $3 \mathrm{mg} \mathrm{cm}^{-2}$ ) using Nafion (NRE 211) membrane. (c) $\mathrm{H}_{2} /$ air fuel cell polarization curve and corresponding power density curve for same MEA from $\mathbf{a}$. A Pt/C $\left(0.4 \mathrm{mg}_{\mathrm{Pt}} \mathrm{cm}^{-2}\right.$ loading) cathode reference was used for comparison. (d) $\mathrm{H}_{2} / \mathrm{O}_{2}$ fuel cell polarization curves of FePhen@MOF-ArNH $\mathrm{N}_{3}$ and $\mathrm{Pt} / \mathrm{C}$ cathode measured initially and after 10K cycles (using $3 \mathrm{~s}$ hold and pulses between 0.6 and $1.0 \mathrm{~V}$ under nitrogen flow).

containing no direct $\mathrm{Fe}-\mathrm{N}_{x}$ coordination (as detailed in subsequent sections). In addition to the exceptional performance, the most impressive characteristic of FePhen@MOF-ArNH $\mathrm{N}_{3}$ was the outstanding stability observed through 10,000 potential cycles (Fig. 2d; protocol in accordance to method shown in Fig. 2 and described in Methods section) that simulates automotive drive cycle conditions. When compared with the state-of-the-art Pt/C MEA (Fig. 2d) subjected to the same test, FePhen@ MOF-ArNH $\mathrm{ALA}_{3}$ MEA proved to be more durable $\left(100 \mathrm{~mA} \mathrm{~cm}{ }^{-2}\right.$ versus $250 \mathrm{~mA} \mathrm{~cm}^{-2}$ (for $\mathrm{Pt} / \mathrm{C}$ reference) current loss at $0.6 \mathrm{~V}_{\text {non-iR corrected }}$ ) and maintained its superior mass-transport properties. Increased carbon graphitization has been reported to improve resistance to carbon corrosion ${ }^{34}$ and one source of enhanced stability of FePhen@MOF-ArNH $\mathrm{N}_{3}$ could be attributed to the presence of CNTs that were observed by SEM/TEM. A variety of harsh testing conditions, such as cycling in the presence of hydrogen peroxide (Supplementary Note 6), have substantiated the findings mentioned above, however only a few representative examples are shown in the present work. The exact origin of durability in FePhen@MOF-ArNH $\mathrm{H}_{3}$ requires more extensive investigation and will be presented in a future publication.

Identification of Fe-coordination. Earlier observations of heattreated $\mathrm{Fe}^{-\mathrm{TPP}^{32}}$ (heat treatment of existing macrocycle) and PVAG-Fe ${ }^{14}$ (Fe-based catalysts prepared from precursors using a reactive polymer approach) clearly indicated the presence of $\mathrm{Fe}-\mathrm{N}_{x}$ active sites in addition to relatively small but stable Fe NPs in both the electrocatalysts despite the different precursors/ synthetic routes used. They also represent different types of defect structures on the carbon and hence Fe spin states. Among the key features associated with $\mathrm{ORR}$ on such $\mathrm{Fe}-\mathrm{N}_{x}$ containing electrocatalyst elucidated using in situ XAS are (a) the $\mathrm{Fe}^{2+}-\mathrm{N}_{4}$ active site undergoes a redox transition to $(\mathrm{H}) \mathrm{O}-\mathrm{Fe}^{3+}-\mathrm{N}_{4}$ between 0.7 and $0.9 \mathrm{~V}$ versus RHE, which correlates with an edge shift of the XANES characteristic of such a change in oxidation state with increasing potential (Fig. 3c,d), and (b) a concomitant increase in the magnitude of the FT peak at $\sim 1.6 \AA$ (associated with $\mathrm{Fe}-\mathrm{N} / \mathrm{O}$ scattering) in the same corresponding potential showing oxide formation on the $\mathrm{Fe}$ in oxidation state 3 (Fig. 3d). Fe $\mathrm{Fe}^{\mathrm{III}}-\mathrm{N}_{x}(\mathrm{OH})$ formation close to $0.9 \mathrm{~V}$ versus $\mathrm{RHE}$ clearly indicated by the forward FT at Fe K-edge (Fig. 3d) also means that the onset of oxygen reduction is intimately related to such a redox transition (this is also supported by redox peaks in alkaline and acidic media). In contrast to these observations on non-PGM catalysts containing $\mathrm{Fe}-\mathrm{N}_{x}$ coordination, the $\mathrm{Fe}$ K-edge FT of the EXAFS for FePhen@MOF-ArNH $\mathrm{H}_{3}$ does not contain the characteristic $\mathrm{Fe}-\mathrm{N} / \mathrm{O}$ peak at $1.6 \AA$ (indicative of $\mathrm{Fe}-\mathrm{N}$ interaction at and below $0.7 \mathrm{~V}$ and an additional $\mathrm{Fe}-\mathrm{O}(\mathrm{H})$ interaction at higher potentials) and is characterized instead by a peak at $\sim 2.2 \AA$ coinciding with Fe-Fe scattering as seen by comparison with characteristic corresponding peaks from metallic $\mathrm{Fe}$ and $\mathrm{Fe}_{3} \mathrm{C}$ standards (Fig. 3a). Furthermore, when the applied potential is increased, the Fe K-edge XANES energy of FePhen@MOF-ArNH $\mathrm{H}_{3}$ remains unchanged. XANES is far more sensitive than EXAFS at detecting the presence of $\mathrm{FeN}_{x}$ species (Supplementary Note 3) and our specialized in situ technique further enhances this response. Moreover, analysis of the ${ }^{57} \mathrm{Fe}$ Mössbauer spectroscopy results unambiguously confirm the absence of $\mathrm{FeN}_{x}$ moieties in FePhen@MOF-ArNH${ }_{3}$. Doublets D1 and D2, identified in all Fe-based non-PGM electrocatalysts investigated with Mössbauer spectroscopy to date, were assigned to $\mathrm{FeN}_{x} \mathrm{C}_{\mathrm{y}}$ moieties covalently integrated in graphene sheets ${ }^{16,35}$. However, the doublet observed with FePhen@MOF-ArNH $\mathrm{H}_{3}$, with isomer shift (IS) and quadrupole splitting values of 0.16 and $0.50 \mathrm{~mm} \mathrm{~s}^{-1}$, respectively, is fundamentally different and can be confidently and entirely assigned to a nitrogen-rich iron nitride crystalline structure (Supplementary Note 5). Hence, it is concluded that $\mathrm{FeN}_{x}$ moieties integrated in graphene sheets are absent in FePhen@MOF-ArNH $\mathrm{H}_{3}$. These findings further confirm 


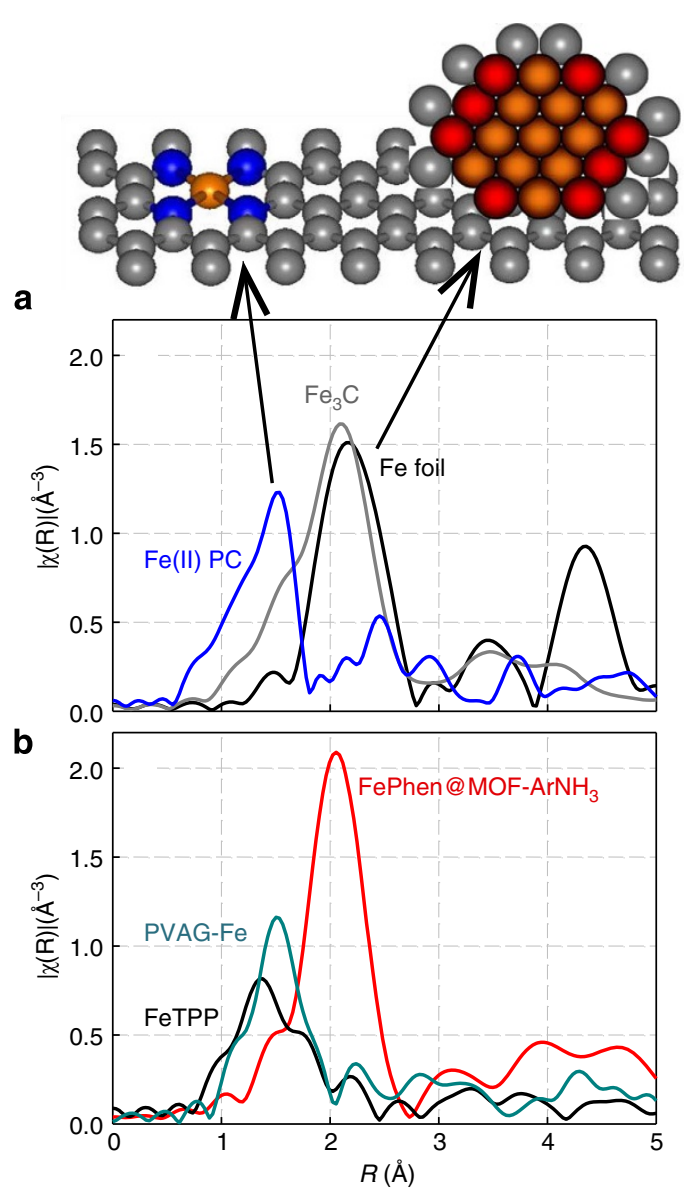

C

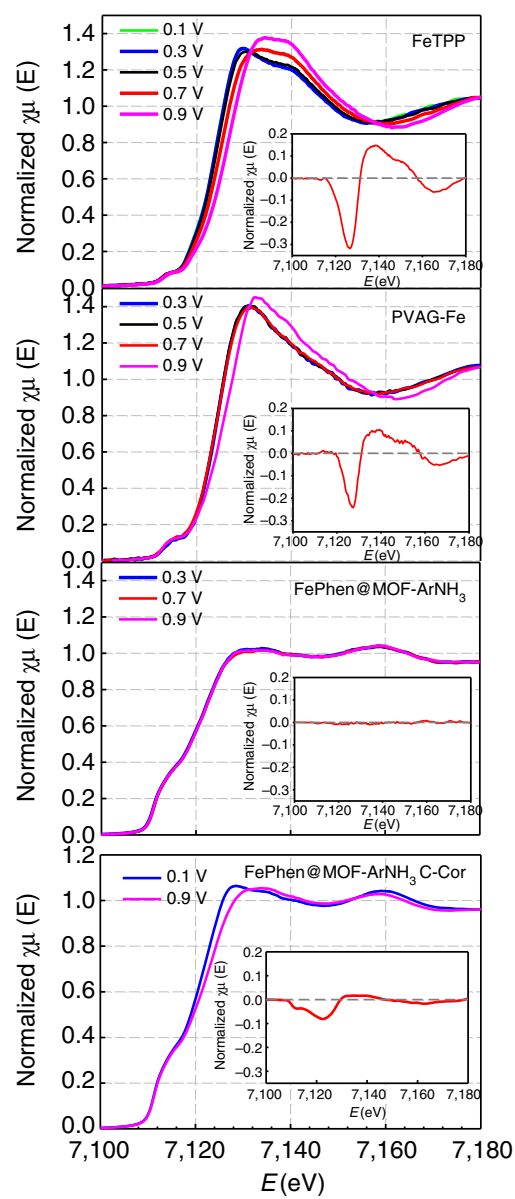

d

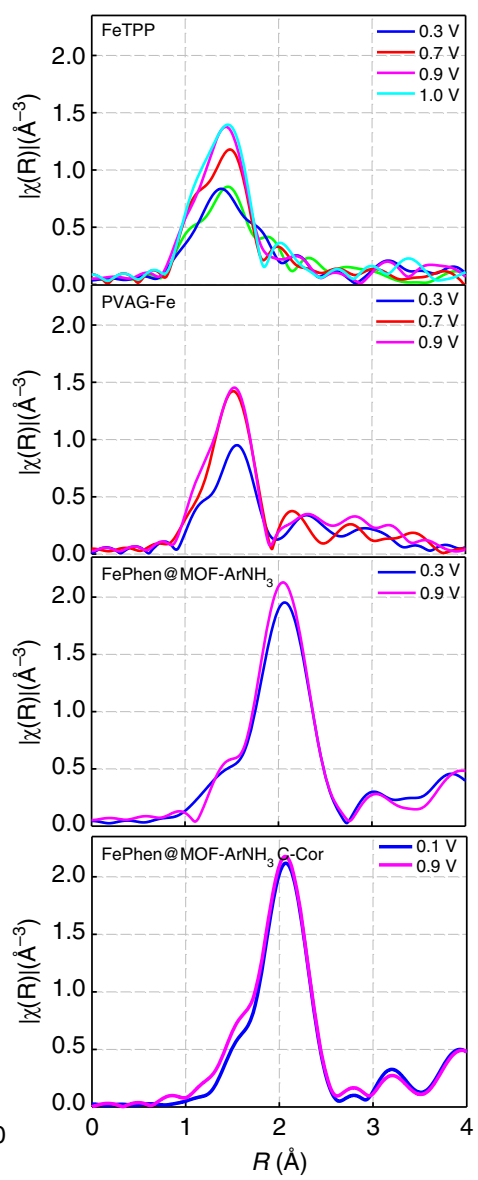

Figure 3 | Structural and electronic investigation of iron in non-PGMs. (a) Fourier transform EXAFS of Fe(II)PC, $\mathrm{Fe}_{3} \mathrm{C}$ and $\mathrm{Fe}$ foil standards collected at Fe K-edge (7,112 eV) (b) Fourier transform EXAFS of FePhen@MOF-ArNH $\mathrm{H}_{3}$, FeTPP pyrolyzed at $800^{\circ} \mathrm{C}$ and PVAG-Fe in $\mathrm{N}_{2}$ saturated $0.1 \mathrm{M}$ HCIO 4 (c) Potential-dependent normalized Fe K-edge XANES of FeTPP, PVAG-Fe, FePhen@MOF-ArNH $\mathrm{A}_{3}$ and carbon-corroded Fe-Phen@MOF-ArNH 3 collected in $\mathrm{N}_{2}$ saturated $0.1 \mathrm{M} \mathrm{HClO}_{4}$; inset difference spectra, $\Delta \mu=\mu(0.9 \mathrm{~V})-\mu(0.3 \mathrm{~V})$. (d) Potential-dependent FT-EXAFS of same electrocatalysts in $\mathbf{b}$ collected in $\mathrm{O}_{2}$ saturated $0.1 \mathrm{M} \mathrm{HClO}_{4}$.

the results presented above using XRD, SEM and TEM in conjunction with electrochemistry. We believe that FePhen@MOF- $\mathrm{ArNH}_{3}$ is predominantly made up of subsurface $\mathrm{Fe} / \mathrm{Fe}_{x} \mathrm{C}$ nanoparticles and there are no detectable $\mathrm{Fe}-\mathrm{N}_{x}$ moieties present when studied under ex situ and in situ conditions. The unique characteristics of XAS enable probing of the coordination environment with element specificity (in this case $\mathrm{Fe}$ ) and in situ capability provides incontrovertible evidence of a highly active non-PGM in acidic media that lacks the direct $\mathrm{Fe}-\mathrm{N}_{x^{-}}$ coordinated active site. To the author's best knowledge, this represents a unique type of active site where lack of direct metal-nitrogen coordination is unambiguously shown using in situ-specific probe of the actual transition metal coordination environment in conjunction with one of the highest reported activity for ORR in acidic and alkaline media.

This conclusion was further supported by subjecting FePhen@ MOF-ArNH $\mathrm{H}_{3}$ electrocatalyst to carbon corrosion cycling in the potential range of $1.0-1.5 \mathrm{~V} \quad\left(100 \mathrm{mV} \mathrm{s}^{-1}\right.$, acidic media; Supplementary Fig. 12). The carbon-corroded FePhen@MOF$\mathrm{ArNH}_{3}$ has the emergence of the signature edge shift in the Fe K-edge XANES spectra seen previously for $\mathrm{FeN}_{x}$-coordinated active sites (Fig. 3c) associated with a $\mathrm{Fe}^{\mathrm{II}}$ to $\mathrm{Fe}^{\mathrm{III}}$ redox transition $(0.7-0.9 \mathrm{~V})$. This clearly indicates the formation of some $\mathrm{FeN}_{x}$ moieties and their direct involvement with the ORR mechanism. On the basis of these results, we conclude that some of the
$\mathrm{Fe} / \mathrm{Fe}_{x} \mathrm{C}$ nanoparticles covered by fewer graphitic sheets are exposed to the acidic environment during the carbon corrosion treatment and are dissolved. This process would then allow some of the dissolved Fe-ions to either (a) adsorb on nitrogen sites that are doped into the carbon matrix to form the $\mathrm{FeN}_{x}$ active site, similar to the active-site formation previously proposed by Yeager et al. ${ }^{31,36,37}$, or (b) form $\mathrm{Fe}^{\mathrm{III}}$ hydroxides $\left(\mathrm{Fe}(\mathrm{OH})_{3}\right)$ as proposed by Goellner et al. ${ }^{38}$

These results also clearly point towards the fact that since FePhen@MOF-ArNH $\mathrm{H}_{3}$ constitutes of subsurface $\mathrm{Fe} / \mathrm{Fe}_{x} \mathrm{C}$-type moieties and their role in any Fenton's-type peroxide-induced free-radical formation is unlikely. Some of the durability results presented (Fig. 2d; Supplementary Figs 13 and 14) are in concert with this observation, especially when compared with $\mathrm{Pt} / \mathrm{C}$. This is a very critical distinction from the $\mathrm{Fe}-\mathrm{N}_{x}$-based non-PGM electrocatalysts.

\section{Discussion}

In this work, we introduced a Fe-based non-PGM ORR electrocatalysts, FePhen@MOF- $\mathrm{ArNH}_{3}$, which utilizes a MOF support that acts as a host for the Fe-based sites. Orderly dispersion of the Fe-chelates is achieved with the encapsulation synthesis and gives rise to an electrocatalyst with high activity for ORR in acidic media and outperforms the benchmark Pt/C catalyst in alkaline media. The exceptional ORR activity measured 
using a RRDE setup in acid translated to the superior PEM fuel cell performance where FePhen@MOF- $\mathrm{ArNH}_{3}$ showed excellent mass-transport properties and stability. Characterization techniques revealed the iron is present as $\mathrm{Fe} / \mathrm{Fe}_{x} \mathrm{C}$ nanoparticles that are subsurface to $\mathrm{N}$-doped carbon overlayer; however, they could play a role in the electrocatalysis by imparting a synergistic effect on the N-doped carbon that allows stabilization of the peroxide intermediate and enables the full $4 \mathrm{e}^{-}$reduction of oxygen to water. What sets this work apart from others is the definitive proof that this exceptionally active non-PGM electrocatalysts lacks direct $\mathrm{Fe}-\mathrm{N}_{x}$ coordination when studied using ex situ ${ }^{57} \mathrm{Fe}$ Mössbauer spectroscopy and in situ synchrotron XAS at the Fe K-edge under simulated conditions of operating PEM cell. All previous reports in the literature have been obtained under $e x$ situ conditions alone and cannot account for catalyst structure changes at the catalyst-electrolyte interface with an applied potential. The lack of evidence suggesting the presence of $\mathrm{Fe}-\mathrm{N}_{x}$ moieties under in situ conditions allows us to conclusively attribute the majority of the ORR activity to the $\mathrm{N}$-doped carbon structure. On the basis of our results, we believe that the iron first acts as a catalyst for the graphitization of $\mathrm{N}$-doped carbon during the heat treatment in which some iron is integrated into the carbon and enhances the electrocatalytic properties enabling the $4 \mathrm{e}^{-}$reduction of oxygen.

\section{Methods}

Catalyst synthesis and electrochemical measurements. The commercial $\mathrm{Pt} / \mathrm{C}$ $(46 \%)$ electrocatalyst used as a standard in this study is obtained from Tanaka Kikinzoku International KK (Japan). For the synthesis of FePhen@MOF, 2-methylimidazole $(5.90 \mathrm{~g}, 0.072 \mathrm{~mol}, 160 \mathrm{eq})$ was dissolved in methanol $(20 \mathrm{ml})$ at RT with stirring in flask A. In flask B, zinc(II) nitrate $\chi$-hydrate $(10.80 \mathrm{~g}, 0.036 \mathrm{~mol}$, $80 \mathrm{eq})$ and 1,10-phenanthroline monohydrate $(12.96 \mathrm{~g}, 0.072 \mathrm{~mol}, 160 \mathrm{eq})$ were dissolved in methanol $(30 \mathrm{ml})$ and water $(45 \mathrm{ml})$ at RT with stirring. Once both flasks' contents were fully dissolved, flask B was added to flask A. Iron(II) acetate $(0.081 \mathrm{~g}, 4.66 \mathrm{E}-4 \mathrm{~mol}, 1 \mathrm{eq})$ was added to the reaction, and this was stirred at RT for $24 \mathrm{~h}$. A second reaction identical to the aforementioned vessel was assembled, and the two separate reactions progressed in tandem. Before the addition of iron(II) acetate, the reaction began to turn slightly milky white/turbid in appearance. This intensified over the course of the reaction, resulting in a fine suspension turbid and pale orange in colour. The two reaction vessels were then combined in $6 \times 50$-ml centrifuge tubes and centrifuged at 4,000 r.p.m. for $25 \mathrm{~min}$, washed three times with methanol $(6-40 \mathrm{ml}$ each time), centrifuging at 3,700 r.p.m. for $17 \mathrm{~min}$ in between each washing. The resulting orange/white solid was dried in a vacuum oven for $6-12 \mathrm{~h}$ at $60-70^{\circ} \mathrm{C}$ and afforded formation of the desired FePhen@MOF, a light tan powder (typically 4.5-5.5 g total yield from the two combined reaction vessels). The dried powder was then subjected to either one or two heat treatments, that is, in argon at $1,050^{\circ} \mathrm{C}$ with a $1 \mathrm{~h}$ dwell time (FePhen@MOF-Ar) and ammonia at $1,050^{\circ} \mathrm{C}$ with an $18 \mathrm{~min}$ dwell time (FePhen@MOF-ArNH $\mathrm{H}_{3}$ ), respectively. The weight per cent of Fe used in the synthesis of FePhen@MOF and its retention throughout the heat treatment process (FePhen@MOF-Ar and FePhen@MOF-ArNH ${ }_{3}$ ) was quantified using inductively coupled plasma mass spectrometry (ICP-MS) and is listed in the (Supplementary Table 4). Perchloric acid electrolyte $(0.1 \mathrm{M})$ was prepared using double-distilled $70 \%$ perchloric acid (GFS Chemicals) and potassium hydroxide electrolyte $(0.1 \mathrm{M})$ was prepared using pellets (Alfa Aesar)

Electrochemical measurements were carried out on glassy carbon disk (5.61-mm diameter, Pine Instruments) that was polished with 0.05-micron alumina paste (Buehler, Lake Bluff, IL) and then sonicated in distilled water and Isopropyl alcohol. Catalysts inks were prepared by dispersing the catalyst in a volume of 1:1 Millipore water:isopropyl alcohol with $10 \mathrm{vol} \%$ of $5 \mathrm{wt} \%$ Nafion as a binder. The ink solution was then sonicated $\sim 60$ min to get a uniform suspension. A small volume of the catalyst ink was deposited on the glassy carbon substrate to obtain a platinum metal loading of $15 \mu \mathrm{g}_{\mathrm{Pt}} \mathrm{cm}^{-2}$ and a non-PGM loading of $\sim 600 \mu \mathrm{g} \mathrm{cm}^{-2}$. All electrochemical measurements were carried out at RT $\left(20-25^{\circ} \mathrm{C}\right)$ in a standard electrochemical cell (Chemglass) with an acid or base electrolyte using a rotating disk electrode (RDE) setup from Pine Instrument Company connected to an Autolab bipotentiostat (PGSTAT302N). Cyclic voltammetry was run on both $\mathrm{Pt}$ and non-PGM catalysts in $0.1 \mathrm{M} \mathrm{HClO}_{4}$ and $0.1 \mathrm{M}$ potassium hydroxide $(\mathrm{KOH})$ bubbled with argon. ORR was investigated by the RDE technique after bubbling oxygen in the electrolyte solution followed with rotations at 100, 400, 900, 1,600 and 2,500 r.p.m. Scans were recorded at $20 \mathrm{mV} \mathrm{s}^{-1}$ and all potentials are referenced to a reversible hydrogen electrode (RHE) scale made from the same solution as the electrolyte. Carbon corrosion treatment of FePhen@MOF- $\mathrm{ArNH}_{3}$ was performed in argon saturated $0.1 \mathrm{M} \mathrm{HClO}_{4}$ by cycling $1-1.5 \mathrm{~V}$ versus RHE at $100 \mathrm{mV} \mathrm{s}^{-1}$ and 1,600 r.p.m. rotation speed for 7,500 cycles.
Hydrogen peroxide cycling test involves cycling (0.05-1.2 V versus RHE) the catalyst under RDE conditions $\left(600 \mu \mathrm{g} \mathrm{cm}^{-2}\right), 0.5 \mathrm{M} \mathrm{H}_{2} \mathrm{SO}_{4}$ with and without $70 \mathrm{mM} \mathrm{H}_{2} \mathrm{O}_{2}$

MEAs for fuel cell testing were prepared using FePhen@MOF-ArNH $\mathrm{H}_{3}$ cathode on gas diffusion layer (GDL, Sigracet BC25 GDL), Pt/C (Tanaka, 46\%) anodes on GDL (Sigracet BC25), Nafion $5 \mathrm{wt} \%$ ionomer solution, and Nafion 211 ionomer membrane. To prepare the cathode, a catalyst ink composed of FePhen@ MOF- $\mathrm{ArNH}_{3}$ dispersed in a water-alcohol mixture with the requisite amount of ionomer (Nafion $5 \mathrm{wt} \%$ ) was sprayed on GDL (Sigracet, BC25). Typical cathode loading consisted of $0.3 \mathrm{mg} \mathrm{cm}^{-2}$ with an ionomer content of $60 \%$ by weight of the catalyst. After drying the cathodes, a layer of interfacial ionomer was sprayed to achieve a loading of $0.4 \mathrm{mg}_{\mathrm{Nafion}} \mathrm{cm}^{-2}$. Anodes were prepared with commercial $\mathrm{Pt} / \mathrm{C}$ (Tanka, 46\%) in the same manner as the cathode. Electrodes for the Pt-based cathode MEA were supplied by industry. Hot pressing of the electrodes together with a Nafion 211 membrane was carried out at $130^{\circ} \mathrm{C}$ and $1,000 \mathrm{lbs}$ for duration of $5 \mathrm{~min}$. MEAs were then assembled in a fuel cell consisting of $5 \mathrm{~cm}^{2}$ serpentine flow fields. Humidification of the MEA was performed for 60 min by flowing $\mathrm{N}_{2}$ $(100 \%$ relative humidity $(\mathrm{RH}))$ at a cell temperature of $80^{\circ} \mathrm{C}$. The operating temperature of the fuel cell was $80^{\circ} \mathrm{C}$ and the cell was activated with $\mathrm{H}_{2} / \mathrm{O}_{2}$ (inlet temperatures $85^{\circ} \mathrm{C}, 100 \% \mathrm{RH}, 22$ p.s.i. back pressure). Durability cycling followed protocols from Nissan Technical Center North America designed to simulate accelerated drive cycle conditions based on transitions between open circuit voltage and idling in automobile operation. Durability was tested at $80^{\circ} \mathrm{C}$ with $\mathrm{N}_{2}$ flowing on the cathode while stepping potential from 0.6 to $1.0 \mathrm{~V}$ versus RHE with $3 \mathrm{~s}$ hold at each potential step.

Physicochemical characterization. X-ray diffraction was performed on a Rigaku (model Ultima-IV) diffractometer with $\mathrm{Cu} \mathrm{K} \alpha$ radiation $(\lambda=1.5418 \AA)$ at $40 \mathrm{kV}$ and $40 \mathrm{~mA}$. The scan speed was $2-20 \mathrm{~s}$ and the step size was $0.1^{\circ}$. ultraviolet-vis quantification performed on Thermo-Fisher ultraviolet-vis spectrophotometer collecting absorbance spectra from 190 to $700 \mathrm{~nm}$. Calibration curve generated from 12.5 to $100.0 \mu \mathrm{M} 1,10$-phenanthroline monohydrate dissolved in $1 \mathrm{M} \mathrm{HCl}$. Three hundred micromolar solutions of FePhen@MOF and Basolite Z1200 standard dissolved in $1 \mathrm{M} \mathrm{HCl}$ were run under the same conditions. Thermogravimetric analyses were performed on TA Instruments SDT Analyzer Q600 from 22 to $1,100^{\circ} \mathrm{C}$ with a ramp rate of $5^{\circ} \mathrm{C} \mathrm{min}^{-1}$ and dwelling for $5 \mathrm{~min}$ at maximum temperature. All studies were conducted under argon atmosphere, with a flow rate of $100 \mathrm{ml} \mathrm{min}-1 . \mathrm{N}_{2}$ sorption analysis was performed on a Quantachrome NOVA $2,200 \mathrm{e}$ at $77 \mathrm{~K}$. Total surface area was determined by the BET method and pore size distribution was determined using non-local DFT split pore method from the NovaWin software. SEM was performed on a Hitachi S-4,900 FSEM instrument with an accelerating voltage of $3-5 \mathrm{keV}$ with samples mounted on a carbonadhesive stub attached to an aluminum sample stage. High-resolution TEM images were taken on a JEOL 2010 field emission gun (FEG) TEM at $200 \mathrm{kV}$ with samples deposited on a holey carbon film on a 300 mesh copper grid.

${ }^{57} \mathrm{Fe}$ Mössbauer spectroscopy was measured with a ${ }^{57} \mathrm{Co}$ source embedded in rhodium matrix. The measurement was performed keeping the source and absorber at RT. The spectrometer was operated with a triangular velocity waveform, and a gas filled proportional counter was used for the detection of the $\gamma$-rays. Velocity calibration was performed with an $\alpha$-Fe foil. The spectra were fitted with a combination of Lorentzian lines. In this way, spectral parameters such as the IS, the electric quadrupole splitting, the linewidth at half maximum, the hyperfine fieldsand the absorption spectral areas of the various spectral components were determined. No constraints were applied to the fitting parameters except on the IS of the singlet assigned to $\gamma$-Fe, fixed at $-0.08 \mathrm{~mm} \mathrm{~s}^{-1}$ on the basis of previous experimental studies on $\mathrm{Fe}-\mathrm{N}-\mathrm{C}$ catalysts showing the presence of the ubiquitous singlet assigned to $\gamma$-Fe.

The in situ XAS studies at the Fe K-edge $(7,112 \mathrm{eV})$ were performed at X3B beamline of National Synchrotron Light Source (Brookhaven National Laboratory, NY, USA). A specially designed spectro-electrochemical cell was employed ${ }^{39}$. The Fe K-edge spectra were collected in fluorescence mode with a 32 -element Ge solid state detector as a function of potential in the range 1.0-0.1 V. A pseudo steady state was established by holding the cell for $\sim 5 \mathrm{~min}$ before collecting the spectra. The electrolyte, $0.1 \mathrm{M} \mathrm{HClO}_{4}$, was saturated with either argon or oxygen. Athena ${ }^{40}$ and Artemis ${ }^{41}$ programs were used to process and fit the data. IFEFFIT suite ${ }^{40}$ was used to calibrate, align and normalize the scans. FEFF6 code ${ }^{42}$ was used to calculate the scattering paths to model the $\chi(\mathrm{R})$ transforms.

\section{References}

1. Jasinski, R. Cobalt phthalocyanine as a fuel cell cathode. J. Electrochem. Soc. 112, 526-528 (1965)

2. Jahnke, H., Schönborn, M. \& Zimmermann, G. in Physical and Chemical Applications of Dyestuffs 133-181 (Springer, 1976).

3. Gupta, S., Tryk, D., Bae, I., Aldred, W. \& Yeager, E. Heat-treated polyacrylonitrile-based catalysts for oxygen electroreduction. J. Appl. Electrochem. 19, 19-27 (1989).

4. Chung, H. T., Won, J. H. \& Zelenay, P. Active and stable carbon nanotube/ nanoparticle composite electrocatalyst for oxygen reduction. Nat. Commun. 4, 1922 (2013). 
5. Wu, G., More, K. L., Johnston, C. M. \& Zelenay, P. High-performance electrocatalysts for oxygen reduction derived from polyaniline, iron, and cobalt. Science 332, 443-447 (2011).

6. Lefèvre, M., Proietti, E., Jaouen, F. \& Dodelet, J.-P. Iron-based catalysts with improved oxygen reduction activity in polymer electrolyte fuel cells. Science 324, 71-74 (2009)

7. Proietti, E. et al. Iron-based cathode catalyst with enhanced power density in polymer electrolyte membrane fuel cells. Nat. Commun. 2, 416 (2011).

8. Lefèvre, M., Dodelet, J. \& Bertrand, P. Molecular oxygen reduction in PEM fuel cells: evidence for the simultaneous presence of two active sites in Fe-based catalysts. J. Phys. Chem. 106, 8705-8713 (2002).

9. Schulenburg, H. et al. Catalysts for the oxygen reduction from heat-treated iron (III) tetramethoxyphenylporphyrin chloride: structure and stability of active sites. J. Phys. Chem. B 107, 9034-9041 (2003).

10. Faubert, G. et al. Heat-treated iron and cobalt tetraphenylporphyrins adsorbed on carbon black: physical characterization and catalytic properties of these materials for the reduction of oxygen in polymer electrolyte fuel cells. Electrochim. Acta 41, 1689-1701 (1996).

11. Gojković, S. L., Gupta, S. \& Savinell, R. F. Heat-treated iron(III) tetramethoxyphenyl porphyrin supported on high-area carbon as an electrocatalyst for oxygen reduction. J. Electrochem. Soc. 145, 3493-3499 (1998).

12. Gojković, S. L., Gupta, S. \& Savinell, R. F. Heat-treated iron(III) tetramethoxyphenyl porphyrin chloride supported on high-area carbon as an electrocatalyst for oxygen reduction: part II. Kinetics of oxygen reduction. J. Electroanal. Chem. 462, 63-72 (1999).

13. Olson, T. S., Pylypenko, S., Fulghum, J. E. \& Atanassov, P. Bifunctional oxygen reduction reaction mechanism on non-platinum catalysts derived from pyrolyzed porphyrins. J. Electrochem. Soc. 157, B54-B63 (2010).

14. Tylus, U. et al. Elucidating oxygen reduction active sites in pyrolyzed metalnitrogen coordinated non-precious electrocatalyst systems. J. Phys. Chem. C 118, 8999-9008 (2014).

15. Wiggins-Camacho, J. D. \& Stevenson, K. J. Mechanistic discussion of the oxygen reduction reaction at nitrogen-doped carbon nanotubes. J. Phys. Chem. C 115, 20002-20010 (2011).

16. Kramm, U. I. et al. Structure of the catalytic sites in Fe/N/C-catalysts for O2-reduction in PEM fuel cells. Phys. Chem. Chem. Phys. 14, 11673-11688 (2012).

17. Qu, L., Liu, Y., Baek, J.-B. \& Dai, L. Nitrogen-doped graphene as efficient metalfree electrocatalyst for oxygen reduction in fuel cells. ACS Nano 4, 1321-1326 (2010).

18. Liu, R., Wu, D., Feng, X. \& Müllen, K. Nitrogen-doped ordered mesoporous graphitic arrays with high electrocatalytic activity for oxygen reduction. Angew. Chem. Int. Ed. 49, 2565-2569 (2010).

19. Maldonado, S. \& Stevenson, K. J. Influence of nitrogen doping on oxygen reduction electrocatalysis at carbon nanofiber electrodes. J. Phys. Chem. B 109, 4707-4716 (2005)

20. Matter, P. H., Zhang, L. \& Ozkan, U. S. The role of nanostructure in nitrogencontaining carbon catalysts for the oxygen reduction reaction. J. Catal. 239, 83-96 (2006).

21. Gong, K., Du, F., Xia, Z., Durstock, M. \& Dai, L. Nitrogen-doped carbon nanotube arrays with high electrocatalytic activity for oxygen reduction. Science 323, 760-764 (2009).

22. Deng, D. et al. Iron encapsulated within pod-like carbon nanotubes for oxygen reduction reaction. Angew. Chem. Int. Ed. 52, 371-375 (2013).

23. Lee, J. S., Park, G. S., Kim, S. T., Liu, M. \& Cho, J. A highly efficient electrocatalyst for the oxygen reduction reaction: N-doped ketjenblack incorporated into $\mathrm{Fe} / \mathrm{Fe} 3 \mathrm{C}$-functionalized melamine foam. Angew. Chem. Int. Ed. 52, 1026-1030 (2013).

24. Wen, Z. et al. Nitrogen-enriched core-shell structured Fe/Fe3C-C nanorods as advanced electrocatalysts for oxygen reduction reaction. Adv. Mater. 24, 1399-1404 (2012).

25. Hu, Y. et al. Hollow spheres of iron carbide nanoparticles encased in graphitic layers as oxygen reduction catalysts. Angew. Chem. Int. Ed. 53, 3675-3679 (2014).

26. Zhang, L. \& Mukerjee, S. Investigation of durability issues of selected nonfluorinated proton exchange membranes for fuel cell application. $J$. Electrochem. Soc. 153, A1062-A1072 (2006)

27. Liédana, N., Galve, A., Rubio, C. S., Téllez, C. \& Coronas, J. CAF@ ZIF-8: one-step encapsulation of caffeine in MOF. ACS Appl. Mater. Interfaces 4, 5016-5021 (2012).

28. Jaouen, F. \& Dodelet, J.-P. Non-noble electrocatalysts for O2 reduction: how does heat treatment affect their activity and structure? Part I. Model for carbon black gasification by NH3: parametric calibration and electrochemical validation. J. Phys. Chem. C 111, 5963-5970 (2007).

29. Park, K. S. et al. Exceptional chemical and thermal stability of zeolitic imidazolate frameworks. Proc. Nat. Acad. Sci. 103, 10186-10191 (2006).
30. Banks, C. E., Davies, T. J., Wildgoose, G. G. \& Compton, R. G. Electrocatalysis at graphite and carbon nanotube modified electrodes: edge-plane sites and tube ends are the reactive sites. Chem. Commun. 829-841 (2005).

31. Yeager, E. Electrocatalysts for $\mathrm{O}_{2}$ reduction. Electrochim. Acta 29, 1527-1537 (1984).

32. Ramaswamy, N., Tylus, U., Jia, Q. \& Mukerjee, S. Activity descriptor identification for oxygen reduction on nonprecious electrocatalysts: Linking surface science to coordination chemistry. J. Am. Chem. Soc. 135, 15443-15449 (2013).

33. Noh, S. H., Kwak, D. H., Seo, M. H., Ohsaka, T. \& Han, B. First principles study of oxygen reduction reaction mechanisms on $\mathrm{N}$-doped graphene with a transition metal support. Electrochim. Acta 140, 225-231 (2014).

34. Wang, X., Li, W., Chen, Z., Waje, M. \& Yan, Y. Durability investigation of carbon nanotube as catalyst support for proton exchange membrane fuel cell. J. Power Sources 158, 154-159 (2006).

35. Koslowski, U. I., Abs-Wurmbach, I., Fiechter, S. \& Bogdanoff, P. Nature of the catalytic centers of porphyrin-based electrocatalysts for the ORR: a correlation of kinetic current density with the site density of Fe - N4 centers. J. Phys. Chem. C 112, 15356-15366 (2008).

36. Scherson, D. et al. Cobalt tetramethoxyphenyl porphyrin-emission Mossbauer spectroscopy and $\mathrm{O}_{2}$ reduction electrochemical studies. Electrochim. Acta 28, 1205-1209 (1983).

37. Scherson, D. et al. Transition metal macrocycles supported on high area carbon: Pyrolysis-mass spectrometry studies. Electrochim. acta 31, 1247-1258 (1986).

38. Goellner, V. et al. Degradation of $\mathrm{Fe} / \mathrm{N} / \mathrm{C}$ catalysts upon high polarization in acid medium. Phys. Chem. Chem. Phys. 16, 18454-18462 (2014).

39. Arruda, T. M. et al. Fundamental aspects of spontaneous cathodic deposition of $\mathrm{Ru}$ onto $\mathrm{Pt} / \mathrm{C}$ electrocatalysts and membranes under direct methanol fuel cell operating conditions: an in situ X-ray absorption spectroscopy and electron spin resonance study. J. Phys. Chem. C 114, 1028-1040 (2009).

40. Newville, M. IFEFFIT: interactive XAFS analysis and FEFF fitting. J. Synchrotron Radiat. 8, 322-324 (2001).

41. Ravel, B. \& Newville, M. ATHENA and ARTEMIS: interactive graphical data analysis using IFEFFIT. Phys. Scr. 2005, 1007 (2005).

42. Zabinsky, S. I., Rehr, J. J., Ankudinov, A., Albers, R. C. \& Eller, M. J. Multiple-scattering calculations of x-ray-absorption spectra. Phys. Rev. B 52, 2995-3009 (1995).

\section{Acknowledgements}

We appreciate financial assistance from the US Department of Energy, EERE (DE-EE-0000459). Use of the National Synchrotron Light Source, Brookhaven National Laboratory (BNL), was supported by the US Department of Energy, Office of Basic Energy Sciences. Synchrotron spectroscopy in this publication was made possible by the Center for Synchrotron Biosciences grant, P30-EB-009998, from the National Institute of Biomedical Imaging and Bioengineering (NIBIB). Support from beamline personnel Dr Erik Farquhar and Mark Chance (X3B) are gratefully acknowledged.

\section{Author contributions}

E.M. synthesized the catalyst and performed XRD and ultraviolet-vis. W.L. performed the TEM. F.J. and M-T.S. performed the Mossbauer measurements and analysed the data. K.S. performed the physical characterization (BET, SEM and XAS), performed RDE measurements and processed the data, prepared fuel cell test materials, conducted fuel cell tests and processed the data. K.S. and Q.J. performed in situ XAS and processed the data. U.T. provided PVAG catalyst. N.R. provided FeTPP catalyst. K.S. and S.M. contributed to the data interpretation and manuscript preparation.

\section{Additional information}

Supplementary Information accompanies this paper at http://www.nature.com/ naturecommunications

Competing financial interests: The authors declare no competing financial interests.

Reprints and permission information is available online at http://npg.nature.com/ reprintsandpermissions/

How to cite this article: Strickland, K. et al. Highly active oxygen reduction non-platinum group metal electrocatalyst without direct metal-nitrogen coordination. Nat. Commun. 6:7343 doi: 10.1038/ncomms8343 (2015).

\section{(i)}

This work is licensed under a Creative Commons Attribution 4.0 International License. The images or other third party material in this article are included in the article's Creative Commons license, unless indicated otherwise in the credit line; if the material is not included under the Creative Commons license, users will need to obtain permission from the license holder to reproduce the material. To view a copy of this license, visit http://creativecommons.org/licenses/by/4.0/ 